\title{
A Study of the Various Factors That Affect the Properties of Molecularly Imprinted Polymers
}

\author{
Takuro Yasuyama, Hirofumi Matsunaga, Shin Ando, and Tadao Ishizuka* \\ Graduate School of Pharmaceutical Sciences, Kumamoto University; 5-1 Oe-honmachi, Chuo-ku, Kumamoto 862- \\ 0972, Japan.
}

Received December 5, 2012; accepted March 6, 2013

\begin{abstract}
We evaluated the adsorbability and selectivity of $(S)$-valine anilide imprinted molecularly imprinted polymer (MIP) using a batch procedure that is both independent and precise. This study revealed important information about the relationship between the performance of MIPs and experimental factors such as the components of MIP synthesis and a reaction solvent. Herein, we also describe the problems associated with the preparation of a "non-imprinted polymer," which is often used to evaluate the effect of a template molecule, and we propose a new type of reference polymer, "blank polymer."
\end{abstract}

Key words $(S)$-valine anilide; molecular imprinting; chiral recognition; non-imprinted polymer; blank polymer

Molecularly imprinted polymers (MIPs) ${ }^{1-4)}$ are widely used as a powerful tool for molecular recognition, due to their high adsorbability and selectivity. Although several methods are available to evaluate the performance of MIPs, the measurement of the separating factor ( $\alpha$-value) using an HPLC column filled with a MIP as a stationary phase ${ }^{5,6)}$ is the most commonly adopted method owing to its simplicity and practical utility.

The $\alpha$-value, however, is affected by many chromatographically experimental factors such as the type of eluent (mobile phase) ${ }^{7)}$ the substrate, ${ }^{8)}$ and the theoretical plate number of the column, and it depends on a large number of recycling adsorption-desorption processes in the stationary phase.

The batch procedure, ${ }^{9)}$ on the other hand, directly measures the concentration of the substrate in a reaction mixture, which allows the precise and independent observation of adsorbability and selectivity. Hence, the batch procedure would be amenable in a study of the relationship between the synthesis conditions of a MIP and its ability.

During the course of our trial to evaluate the performance of MIPs using the batch procedure, we gained important information about the relationship between the performance of MIPs and the many factors involved in the processes of synthesis and measurement.

In this paper, we report the factors that directly affected the properties of the MIPs. We also describe the problems associated with the preparation of a "blank polymer," which is often used as a reference polymer for the sake of comparison.

\section{Experimental}

General Ethylene glycol dimethacrylate (EGDM), methacrylic acid (MAA) and chloroform were freshly distilled prior to use. Alanine, valine, phenylalanine, methacryloyl chloride, 2,2'-azobis(isobutyronitrile) (AIBN), tert-leucine, 1,6-diaminohexane, 2-aminoethanol, $p$-toluenesulfonyl chloride, cyclohexane, dimethyl sulfoxide (DMSO), and propionitrile were purchased and used without further purification. $n$-Hexane, isopropanol, EtOH, and acetonitrile were all HPLC grade and used without further purification. Tetrahydrofuran

The authors declare no conflict of interest.
(THF) (dehydrated) and $\mathrm{CH}_{2} \mathrm{Cl}_{2}$ (dehydrated) were purchased (Kanto Chemical, Co., Inc.), stored under an argon atmosphere and used without further purification. Ethyl acetate and $\mathrm{MeOH}$ were purified by distillation.

\section{Synthesis}

Amino Acid Derivative All amino anilides (1-5) were synthesized according to a previously reported procedure that included the protection of the amino moiety by a tertbutoxycarbonyl (BOC) group, and subsequent amidation using a mixed anhydride method ${ }^{10)}$ followed by the removal of the BOC group. ${ }^{11)}$ All compounds were previously reported, and compounds 1-7 were identified by ${ }^{1} \mathrm{H}-\mathrm{NMR}$.

$(S)$-Valine Anilide (1) and $(R S)$-Valine Anilide (2) ${ }^{12)}$ : Pale yellow oil; ${ }^{1} \mathrm{H}-\mathrm{NMR}\left(300 \mathrm{MHz} / \mathrm{CDCl}_{3}\right) \quad \delta$ : 9.49 (1H, brs), 7.62-7.61 (2H, m), 7.35-7.29 (2H, m), 7.12-7.06 (1H, m), 3.38 $(1 \mathrm{H}, \mathrm{d}, J=3.1 \mathrm{~Hz}), 2.49-2.40(1 \mathrm{H}, \mathrm{m}), 1.05(3 \mathrm{H}, \mathrm{d}, J=7.0 \mathrm{~Hz})$, $0.88(3 \mathrm{H}, \mathrm{d}, J=7.0 \mathrm{~Hz})$.

$(R S)$-Alanine Anilide (3) ${ }^{12)}$ : Pale yellow oil; ${ }^{1} \mathrm{H}-\mathrm{NMR}$ $\left(300 \mathrm{MHz} / \mathrm{CDCl}_{3}\right) \quad \delta: 9.47$ (1H, brs), 7.62-7.58 (2H, m), $7.36-7.28(2 \mathrm{H}, \mathrm{m}), 7.12-7.07(1 \mathrm{H}, \mathrm{m}), 3.65(1 \mathrm{H}, \mathrm{q}, J=7.1 \mathrm{~Hz})$, $1.44(3 \mathrm{H}, \mathrm{d}, J=7.1 \mathrm{~Hz})$.<smiles>CC(C)C(N)C(=O)Nc1ccccc1</smiles>

2<smiles>NC(Cc1ccccc1)C(=O)Nc1ccccc1</smiles>

4<smiles>C=C(C)C(=O)NCCCCCCNC(=O)C(=C)C</smiles><smiles>CC(N)C(=O)Nc1ccccc1</smiles>

3<smiles>CC(C)(C)C(N)C(=O)Nc1ccccc1</smiles>

5

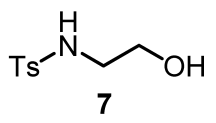

Fig. 1. Structures of Amino Anilides 1-5, Diamide Linker 6 and TsC2AA 7 
$(R S)$-Phenylalanine Anilide $(4)^{12)}$ : Pale yellow solid; ${ }^{1} \mathrm{H}$ NMR (300 MHz/CDCl $) \delta: 9.41(1 \mathrm{H}$, brs), 7.61-7.58 $(2 \mathrm{H}, \mathrm{m})$, 7.37-7.24 (7H, m), 7.14-7.08 (1H, m), 3.75 (1H, dd, $J=9.5$, $4.0 \mathrm{~Hz}), 3.39(1 \mathrm{H}, \mathrm{dd}, J=13.6,4.0 \mathrm{~Hz}), 2.79(1 \mathrm{H}, \mathrm{dd}, J=13.6$, 9.5 Hz).

$(R S)$-tert-Leucine Anilide (5) ${ }^{13)}$ : Colorless amorphous solid; ${ }^{1} \mathrm{H}-\mathrm{NMR}\left(300 \mathrm{MHz} / \mathrm{CDCl}_{3}\right) \delta: 9.00(1 \mathrm{H}, \mathrm{brs}), 7.59-7.56(2 \mathrm{H}$, m), 7.35-7.30 (1H, m), 7.12-7.06 (1H, m), $3.27(1 \mathrm{H}, \mathrm{s}), 1.07$ $(9 \mathrm{H}, \mathrm{s})$.

$N, N^{\prime}$-Dimethacryl Hexylenediamide (DMAH) (6): Compound $\mathbf{6}$ was synthesized by a previously reported procedure. $^{14)}$

Colorless solid; ${ }^{1} \mathrm{H}-\mathrm{NMR}\left(300 \mathrm{MHz} / \mathrm{CDCl}_{3}\right) \delta: 5.99(2 \mathrm{H}$, brs), $5.31(2 \mathrm{H}, \mathrm{s}), 5.68(2 \mathrm{H}, \mathrm{s}), 3.27-3.34(4 \mathrm{H}, \mathrm{m}), 1.96(6 \mathrm{H}, \mathrm{s})$, $1.53-1.57$ (4H, m), 1.37-1.40 (4H, m).

$N$ - $p$-Toluenesulfonyl-2-aminoethanol (Ts-C2AA) (7): Compound 7 was synthesized by a previously reported procedure. ${ }^{15)}$

Colorless solid; ${ }^{1} \mathrm{H}-\mathrm{NMR}\left(300 \mathrm{MHz} / \mathrm{CDCl}_{3}\right) \quad \delta: 7.77 \quad(2 \mathrm{H}$, d, $J=1.8 \mathrm{~Hz}), 7.75(2 \mathrm{H}, \mathrm{d}, J=1.8 \mathrm{~Hz}), 5.26(1 \mathrm{H}, \mathrm{t}, J=6.2 \mathrm{~Hz})$, 3.72-3.68 (2H, m), 3.11-3.08 (2H, m), $2.43(3 \mathrm{H}, \mathrm{s}), 2.27(1 \mathrm{H}, \mathrm{t}$, $J=5.04 \mathrm{~Hz}$ ).

\section{General Procedure for the Preparation of Polymers}

Preparation of a Molecular-Imprinted Polymer (MIP), a Non-imprinted Polymer (NIP), and a Blank Polymer (BP) (Table 1) We prepared several types of polymers as follows. Thus, $(S)$-valine anilide-imprinted MIP (IP-1) was prepared by the polymerization of a mixture of $(S)$-valine anilide (1), ethylene glycol dimethacrylate (EGDM), methacrylic acid (MAA), and AIBN in chloroform under irradiation followed by an appropriate amount of grinding and washing. In a similar manner, NIP-1 was prepared by following the IP-1 procedure with the exception of the absence of template molecule 1. BP-1 was prepared in the presence of isopropylamine, not template molecule $\mathbf{1}$. In a glass vial, $1(1.00 \mathrm{mmol})$ was dissolved in chloroform $(4.0 \mathrm{~mL})$. To this solution were added MAA (4.01 mmol), EGDM (15.9 mmol) and AIBN (0.202 mmol). After sufficient mixing, the solution was separated into four borosilicate screw-capped test tubes and each test tube was flushed with argon gas followed by irradiation with a $100 \mathrm{~W}$ high-pressure mercury vapor lamp $\left(5^{\circ} \mathrm{C}, 8 \mathrm{~h}\right)$ to form a polymer. Bulk polymers were ground with a mill (OSAKA chemical, Wonder Blender, WB-1) and a ball mill (Nitto kagaku, ANZ-50S). Then these were sieved through a $500 \mu \mathrm{m}$ mesh filter, and particles of $<500 \mu \mathrm{m}$ were collected. The polymer was washed (by soxhlet extractor $(\mathrm{MeOH}-\mathrm{AcOH}=7: 3), 20 \mathrm{~h}$ ), filtered (kiriyama funnel (filter paper: No. 5B)), then washed again $\left(\mathrm{CH}_{2} \mathrm{Cl}_{2}\right)$ and dried in vacuo.

General Procedure for Evaluating the Ability of a MIP Using the "Batch Procedure" In a glass vial, $2(5.2 \mu \mathrm{mol})$ was dissolved in $\mathrm{CH}_{2} \mathrm{Cl}_{2}(20 \mathrm{~mL})$. This concentration was defined as $[2]_{0}$, which was an average of $[2]_{S 0}$ (concentration value of $(S)$-form) and $[2]_{R 0}$ (concentration value of $(R)$-form). To this solution was added MIP $(55.2 \mathrm{mg}, 15.6 \mu \mathrm{mol}$ as recognizing sites), followed by stirring at $24^{\circ} \mathrm{C}$ for $2 \mathrm{~h} .{ }^{16)}$ The MIP was filtered off, and the concentration of this filtrate was defined as $[2]_{S}$ and $[2]_{R}$.

$[2]_{0}$ and [2] were determined by HPLC, ${ }^{17)}$ and Ts-C2AA(7) was used as an internal standard. The adsorbed amount and selectivity were calculated using the following equations:

adsorbed amount of $S$ form:

$$
S_{\text {ad }}(\%)=\left\{\left([2]_{0}-[2]_{S}\right) /[2]_{0}\right\} \times 100
$$

adsorbed amount of $R$ form:

$$
R_{\mathrm{ad}}(\%)=\left\{\left([2]_{0}-[2]_{R}\right) /[2]_{0}\right\} \times 100
$$

enantiomeric excess in solution (\%e.e.s.)

$$
=\left\{\left([2]_{S}-[2]_{R}\right) /\left([2]_{S}+[2]_{R}\right)\right\} \times 100
$$

enantiomeric excess in solution (\%e.e.p.)

$$
=\left\{\left(S_{\mathrm{ad}}-R_{\mathrm{ad}}\right) /\left(S_{\mathrm{ad}}+R_{\mathrm{ad}}\right)\right\} \times 100
$$

$S_{\text {ad }}$ and $R_{\text {ad }}$ were used as the indices of adsorbability, and e.e.p. was used as an index of selectivity.

\section{Results and Discussion}

The Effect of a Solvent The affinity between the substrate in the measurement process and the MIP greatly affected not only the properties of the MIP but also those of the solvent, because the adsorption of a compound onto a MIP in a suspension is the result of a liquid-solid equilibrium. Hence, we first studied the effect of the solvents used in the batch procedure. We measured the adsorbability and selectivity of the $(S)$-valine anilide-imprinted MIP in a mixed solvent. $\mathrm{CH}_{2} \mathrm{Cl}_{2}$ was chosen as the base solvent, because of the higher solubility of its amino anilides and an appropriate polarity.

Table 2 shows the effects of the non-polar co-solvent, cyclohexane, which was used as an additive for the batch procedure in $\mathrm{CH}_{2} \mathrm{Cl}_{2}$. Thus, the amount of adsorption for both enantiomers $\left(S_{\mathrm{ad}}, R_{\mathrm{ad}}\right)$ was improved in proportion to the added amount of cyclohexane. This might have been caused by a decrease in the polarity of the liquid phase, as opposed to that of a polymer in the solid phase, whereby the polar amino anilide gathers preferentially to the polymer rather than to the solvent.

On the other hand, in place of a non-polar co-solvent, the addition of polar co-solvents led to the opposite phenomena (Table 3). Interestingly, with the addition of polar solvents such as $\mathrm{MeOH}, \mathrm{EtOH}$ and DMSO, the adsorption of the $(R)$ amino anilide was decreased more drastically than that of the

\begin{tabular}{|c|c|c|c|c|c|c|c|}
\hline Entry & Polymer & 1 (mmol) & $\begin{array}{l}\text { Isopropylamine } \\
(\mathrm{mmol})\end{array}$ & EGDM (mmol) & $6(\mathrm{mmol})$ & MAA (mmol) & $\mathrm{CHCl}_{3}(\mathrm{~mL})$ \\
\hline 1 & IP-1 & 1 & - & 16 & - & 4 & 4 \\
\hline 2 & BP-1 & - & 1 & 16 & - & 4 & 4 \\
\hline 3 & NIP-1 & - & - & 16 & - & 4 & 4 \\
\hline 4 & IP-2 & 1 & - & - & 16 & 4 & 8 \\
\hline 5 & BP-2 & - & 1 & - & 16 & 4 & 8 \\
\hline 6 & NIP-2 & - & - & - & 16 & 4 & 8 \\
\hline
\end{tabular}
$(S)$-isomer, and the e.e.p. values were retained.

These results indicated that the polarity of the solvents

Table 1. Composition of Polymers 
Table 2. Effects of a Non-polar Co-solvent ${ }^{a)}$

\begin{tabular}{clcccc}
\hline \hline Entry & \multicolumn{1}{c}{ Solvent } & $S_{\text {ad }}(\%)$ & $R_{\text {ad }}(\%)$ & e.e.p. (\%) & e.e.s. $(\%)$ \\
\hline 1 & $\mathrm{CH}_{2} \mathrm{Cl}_{2}$ & 45 & 30 & 20 & 12 \\
2 & $\mathrm{CH}_{2} \mathrm{Cl}_{2}-\mathrm{c}-\mathrm{Hex}=75: 25$ & 46 & 29 & 22 & 13 \\
3 & $\mathrm{CH}_{2} \mathrm{Cl}_{2}-\mathrm{c}-\mathrm{Hex}=50: 50$ & 57 & 40 & 17 & 16 \\
4 & $\mathrm{CH}_{2} \mathrm{Cl}_{2}-\mathrm{c}-\mathrm{Hex}=25: 75$ & 70 & 56 & 11 & 19 \\
\hline
\end{tabular}

a) All experiments were used $\mathbf{2}$ as a substrate and IP-1 as polymer.

Table 3. Effcts of Polar Co-solvents ${ }^{a}$

\begin{tabular}{clcccc}
\hline \hline Entry & \multicolumn{1}{c}{ Solvent } & $S_{\text {ad }}(\%)$ & $R_{\text {ad }}(\%)$ & e.e.p. $(\%)$ & e.e.s. $(\%)$ \\
\hline 1 & $\mathrm{CH}_{2} \mathrm{Cl}_{2}$ & 45 & 30 & 20 & 26 \\
2 & $\mathrm{CH}_{2} \mathrm{Cl}_{2}-\mathrm{EtOAc}=90: 10$ & 38 & 22 & 26 & 22 \\
3 & $\mathrm{CH}_{2} \mathrm{Cl}_{2}-\mathrm{CH}_{3} \mathrm{CN}=90: 10$ & 43 & 25 & 34 & 13 \\
4 & $\mathrm{CH}_{2} \mathrm{Cl}_{2}-\mathrm{CH}_{3} \mathrm{CN}=50: 50$ & 30 & 15 & 74 & 10 \\
5 & $\mathrm{CH}_{2} \mathrm{Cl}_{2}-\mathrm{MeOH}=90: 10$ & 14 & $<1$ & $>85$ & 5 \\
6 & $\mathrm{CH}_{2} \mathrm{Cl}_{2}-\mathrm{MeOH}=85: 15$ & 10 & $<1$ & $>85$ & 6 \\
7 & $\mathrm{CH}_{2} \mathrm{Cl}_{2}-\mathrm{EtOH}=90: 10$ & 13 & $<1$ & $>85$ & 3 \\
8 & $\mathrm{CH}_{2} \mathrm{Cl}_{2}-\mathrm{DMSO}=90: 10$ & 6 & 19 & 12 & 4 \\
\hline
\end{tabular}

a) All experiments were used $\mathbf{2}$ as a substrate and IP-1 as polymer.

Table 4. Differences of Substrate ${ }^{a)}$

\begin{tabular}{|c|c|c|c|c|c|c|}
\hline Entry & Substrate & $S_{\text {ad }}(\%)$ & $R_{\mathrm{ad}}(\%)$ & e.e.p. $(\%)$ & e.e.s. $(\%)$ & $\alpha$-Value ${ }^{b}$ \\
\hline 1 & & 36 & 25 & 18 & 8 & 4.38 \\
\hline 2 & & 45 & 30 & 20 & 12 & 30.5 \\
\hline 3 & & 22 & 15 & 20 & 4 & 1.51 \\
\hline 4 & & 38 & 26 & 18 & 9 & - \\
\hline
\end{tabular}

a) All experiments were wsed $\mathrm{CH}_{2} \mathrm{Cl}_{2}$ as solvent and IP-1 as polymer. b) See ref. 12 .

could be used to regulate the adsorbability of a MIP, but the nature of the solvents did not greatly affect the selectivity of the adsorption.

Details of the $\boldsymbol{\alpha}$-Value The valine anilide-imprinted MIP, that was used in the HPLC column, can reportedly separate the enantiomers of other amino anilides that have a similar $\alpha$ substituent. ${ }^{12)}$ But the $\alpha$-values of the amino anilides were apparently different from those of the valine anilide. The $\alpha$-values of the valine anilide, used as a template of the MIP, were much larger than those of other amino anilides. Based on the $\alpha$-value, the MIP mostly showed selectivity only for the template molecule. To establish a precise evaluation system for the MIP, we tried to use the batch procedure to separately evaluate the adsorbability and selectivity of a $(S)$-valine anilide-imprinted MIP (IP-1). A racemic mixture of amino anilide, $(R S)$-alanine anilide (3), $(R S)$-phenylalanine anilide (4), and $(R S)$-tert-leucine anilide (5), which had a similar polarity but a different size of side chain, were used as the substrates in $\mathrm{CH}_{2} \mathrm{Cl}_{2}$ (Table 4).

As a result, there were no distinct differences in selectivity among the substrates, even though extremely different $\alpha$-values were reported by the HPLC evaluation procedure. Table 4 shows that the polymer IP-1, imprinted by the $(S)$ valine anilide, had almost the same selectivities as substrates 2-5.

But, as Table 4 shows, the substrates had a different adsorbability $\left(S_{\mathrm{ad}}+R_{\mathrm{ad}}\right)$ to MIPs. Thus, IP-1 interacted equally with the $(S)$-amino anilide (3-5), possessing smaller and larger sizes of the $\alpha$ substituent than valine, but the total adsorbabilities of $S_{\mathrm{ad}}+R_{\mathrm{ad}}$ depended on the steric size of the $\alpha$ substituent. Valine anilide had the largest affinity for MIPs, $S_{\text {ad }}+R_{\text {ad }}=75 \%$, and lower affinities were shown by the substrates with different sizes of side chain substituents (entries 1 and 3). These differences in adsorbabilities conclusively affected the $\alpha$-values of each of the substrates. Repeated adsorption-desorption cycles under the solid-liquid equilibrium 
Table 5. The Effect of DMAH ${ }^{a}$

\begin{tabular}{|c|c|c|c|c|c|}
\hline Entry & Polymer & $S_{\mathrm{ad}}(\%)$ & $R_{\mathrm{ad}}(\%)$ & e.e.p. $(\%)$ & e.e.s. $(\%)$ \\
\hline 1 & IP-1 & 45 & 30 & 20 & 12 \\
\hline $2^{b)}$ & BP-1 & 30 & 30 & - & - \\
\hline $3^{c)}$ & NIP-1 & 17 & 17 & - & - \\
\hline 4 & IP-2 & 20 & 13 & 20 & 4 \\
\hline $5^{d)}$ & BP-2 & 14 & 14 & - & - \\
\hline $6^{e)}$ & NIP-2 & 9 & 9 & - & - \\
\hline
\end{tabular}

a) All experiments were used $\mathrm{CH}_{2} \mathrm{Cl}_{2}$ as solvent, and $\mathbf{2}$ as substrate. $b$ ) Standard deviation (S.D.: $n=5$ ): $0.96 \%$ for $S_{\text {ad }} ; 0.84 \%$ for $R_{\text {ad }} c$ ) S.D. value $\left(n=5\right.$ ): $1.14 \%$ for $S_{\text {ad }}$; $1.64 \%$ for $R_{\text {ad }}$. d) S.D. value $(n=4): 1.18 \%$ for $S_{\text {ad }} ; 0.71 \%$ for $R_{\text {ad }}$ e) S.D. value $(n=4): 2.09 \%$ for $S_{\text {ad }} ; 1.46 \%$ for $R_{\text {ad }}$.

in the HPLC column amplified the MIP selectivity $\alpha$-value, which is a good index for separation. However, the selectivity of the MIPs tended to be over-estimated when using the $\alpha$-values from our results shown in Table 4 .

The Effect of Changing the Components of the MIP Based on the information concerning the performance of the MIP, as described in the previous sections, we increased the polarity of the MIP. An improvement in adsorbability was needed to attain a higher $\alpha$-value, as shown in Tables 2-4 where the anilide substrate clearly gathered preferentially to the polar phase. A new MIP, IP-2, was synthesized using the amide linker DMAH (6), in place of the ester linker EGDM, and its abilities were evaluated via the batch procedure (Table 5).

Contrary to our expectations, IP-2 showed lower adsorbabilities than IP-1 (entry 4). The e.e.p. value of IP-2, however, was the same as that of IP-1. Therefore, we speculated that IP-2 recognized the molecule in the same manner as IP-1. Because of the interaction between the carboxylic acid moiety of the methacrylic acid (MAA) residue and the amide moiety of diamide linker 6, some part of the necessary interaction was lost, which left only an insufficient amount of the recognition site.

This type of behavior for the functional monomer MAA is also expected in the absence of the template molecule. Thus, in a non-imprinted polymer (NIP; prepared in the absence of the template molecule), which is used for comparison to confirm the effectiveness of the template, a similar phenomenon would occur and lead to an inappropriate effect for adsorbability when comparing the selectivity of an MIP. Therefore, we evaluated the adsorbability of a non-imprinted polymer (NIP) and a blank polymer (BP), which was synthesized in the presence of isopropylamine, an amine with an unrelated steric structure substituent, in place of a template molecule (Table 5).

As a result, the total amount of adsorption $\left(S_{\mathrm{ad}}+R_{\mathrm{ad}}\right)$ for the NIPs was considerably decreased regardless of the species of the cross-linker, the EGDM or the DMAH (entries 3 and 6).

We speculated that most of the MAA would form a dimer and polymerize to afford NIPs (Fig. 2b). Therefore, there was a limited amount of free carboxylic acid residue to interact with the amine moiety of the substrate, which resulted in a low adsorbability.

On the other hand, in the case of BPs, the MAA interacted with isopropylamine, which prevented the dimerization of MAA during polymerization, and many free carboxylic acid moieties and spaces remained after the removal of the isopropylamine to give an adsorbability that was higher than that of the NIPs and similar to that of the IPs. In the case of BP-1, a) IP and BP<smiles>[R]N[I]OC(=O)C(C)(C)C</smiles>

b) NIP

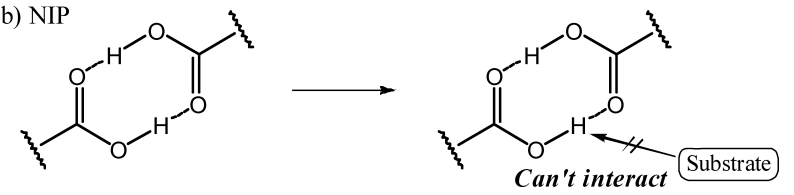

Fig. 2. Plausible Coordination Model of Carboxylic Acid Moieties in IP, BP and NIP

only the affinity for the $(S)$-valine anilide, $S_{\text {ad }}$, was reduced by comparison with that of IP-1. This result obviously shows that BP-1 possesses an adsorbability that is similar to that of IP-1 with the exception of a lack of molecular imprinting for recognition. Therefore, we clearly concluded that BP is a better polymer than NIP for the sake of comparison in order to correctly judge the effect of a MIP template molecule.

\section{Conclusion}

We evaluated the performance of a $(S)$-valine anilideimprinted MIP using the batch procedure in place of a chromatographic method ( $\alpha$-value). Thus, the adsorbability and selectivity of a MIP could be separately measured, and the differences in the properties of MIPs proved to greatly depend on the polarity of the solvent and on the component of the MIP. For the preparation of a MIP with high separation ability, the adsorbability and selectivity should be directly measured using the batch procedure.

The evaluation method used for the preparation of highly efficient MIPs is now being used in research to determine a monomeric additive that can change the abilities of a MIP.

\section{References and Notes}

1) "Molecularly Imprinted Polymers: Man Made Mimics of Antibodies and Their Application in Analytical Chemistry," ed. by Sellergren B., Elsevier, 2001.

2) Takeuchi T., Matsui J., Acta Polym., 47, 471-480 (1996).

3) Kempe M., Mosbach K., J. Chromatogr. A, 694, 3-13 (1995).

4) Alexander C., Andersson H. S., Andersson L. I., Ansell R. J., Kirsch N., Nicholls I. A., O’Mahony J., Whitcombe M. J., J. Mol. Recognit., 19, 106-180 (2006).

5) Lepistö M., Sellergren B., J. Org. Chem., 54, 6010-6012 (1989).

6) Matsui J., Nicholls I. A., Takeuchi T., Tetrahedron Asymmetry, 7, 1357-1361 (1996).

7) Yu C., Mosbach K., J. Chromatogr. A, 888, 63-72 (2000).

8) Ramström O., Yu C., Mosbach K., J. Mol. Recognit., 9, 691-696 
Table 6. Correlation between the Temperature-Reaction Time and $S_{\text {ad }} / R_{\text {ad }}$ Using IP-1 in $\mathrm{CH}_{2} \mathrm{Cl}_{2}$

\begin{tabular}{|c|c|c|c|c|c|c|}
\hline Entry & Temp. $\left({ }^{\circ} \mathrm{C}\right)$ & Time (h) & $S_{\text {ad }}(\%)$ & $R_{\mathrm{ad}}(\%)$ & e.e.p. $(\%)$ & e.e.s. $(\%)$ \\
\hline 1 & 0 & 2 & 56 & 45 & 11 & 11 \\
\hline 2 & 24 & 0.5 & 42 & 32 & 13 & 8 \\
\hline 3 & 24 & 1 & 44 & 35 & 11 & 7 \\
\hline 4 & 24 & 2 & 46 & 37 & 11 & 8 \\
\hline 5 & 40 & 2 & 49 & 37 & 14 & 10 \\
\hline
\end{tabular}

a) All experiments were carried out in $\mathrm{CH}_{2} \mathrm{Cl}_{2}$ as solvent, and $(R S)$-valine anilide was used as substrate.

(1996).

9) Tunc Y., Hasirci N., Yesilada A., Ulubayram K., Polymer, 47, 69316940 (2006).

10) Katritzky A. R., Xu Y.-J., He H.-Y., Steel P. J., J. Chem. Soc., Perkin Trans. 1, 2001, 1767-1770 (2001).

11) Liu Y.-S., Zhao C., Bergbreiter D. E., Romo D., J. Org. Chem., 63, 3471-3473 (1998).

12) Simon R., Collins M. E., Spivak D. A., Anal. Chim. Acta, 591, 7-16 (2007).

13) Beckett R. P., Whittaker M., Miller A., Martin F. M., PCT. Int. Appl., WO 9519956 A1 (1995).

14) Shea K. J., Stoddard G. J., Shavelle D. M., Wakui F., Choate R. M., Macromolecules, 23, 4497-4507 (1990).

15) Fukudome Y., Naito H., Hata T., Urabe H., J. Am. Chem. Soc., 130, 1820-1821 (2008).

16) Correlation between the temperature/reaction time and $S_{\text {ad }} / R_{\text {ad }}$ using IP-1 in $\mathrm{CH}_{2} \mathrm{Cl}_{2}$ were also tested (Table 6). (Note: The lot No. of IP-1 used in Table 6 and that used in Tables 2-5 were different and therefore $S_{\text {ad }}$ and $R_{\text {ad }}$ in entry 4, Table 6, gave the values that were slightly different from those in Tables $2-5$.) At $0^{\circ} \mathrm{C}$, adsorbed amount was increased with the same e.e.p. value as in $24^{\circ} \mathrm{C}$ (entries 1 and 4), causing from the stabilization of polymer-substrate com- plex. On the other hand, higher temperature such as $40^{\circ} \mathrm{C}$ gave the similar adsorbability as in $24^{\circ} \mathrm{C}$. Reducing the adsorption time such as $0.5 \mathrm{~h}$ showed slightly reduced adsorbability. From these results, we concluded that the adsorption of substrate with polymer would proceeded to be equilibrated for $2 \mathrm{~h}$ at $24^{\circ} \mathrm{C}$, and therefore adopted as the standard condition of the evaluation because of the easiness of handling and reproducibility.

17) HPLC conditions are as follows. Table 2, Table 3; entry1 7, 9, Table 4; entry 2 and Table 5: DAICEL CHIRALPAK IA, hexane-EtOH$\mathrm{DEA}=85: 15: 0.1,1.0 \mathrm{~mL} / \mathrm{min}, 254 \mathrm{~nm}$, internal standard was 7 , $t_{\mathrm{R}}=7.1 \mathrm{~min}(S), 8.9 \mathrm{~min}(R), 21.3 \mathrm{~min}(7)$. Table 3 ; entry 8 : DAICEL CHIRALPAK IC, hexane-IPA-DEA $=80: 20: 0.4, \quad 0.7 \mathrm{~mL} / \mathrm{min}$, $254 \mathrm{~nm}$, internal standard was cinchonine, $t_{\mathrm{R}}=8.8 \mathrm{~min}$ (cinchonine), $11.6 \mathrm{~min}(R), 13.6 \mathrm{~min}(S)$. Table 4 ; entry 1: DAICEL CHIRALPAK IC, hexane-IPA-DEA $=80: 20: 0.4,1.0 \mathrm{~mL} / \mathrm{min}, 254 \mathrm{~nm}$, internal standard was cinchonine, $t_{\mathrm{R}}=6.2 \mathrm{~min}$ (cinchonine), $10.4 \mathrm{~min}(S)$, $15.4 \mathrm{~min}(R)$. Table 4; entry 3: DAICEL CHIRALPAK IA, hexane-IPA-DEA $=90: 10: 0.5,1.5 \mathrm{~mL} / \mathrm{min}, 254 \mathrm{~nm}$, internal standard was $7, t_{\mathrm{R}}=9.6 \mathrm{~min}(R), 11.6 \mathrm{~min}(S), 15.0 \mathrm{~min}$ (7). Table 4; entry 4: DAICEL CHIRALPAK IA, hexane-EtOH-DEA $=85: 15: 0.1$, $1.0 \mathrm{~mL} / \mathrm{min}, 254 \mathrm{~nm}$, internal standard was $7, t_{\mathrm{R}}=7.1 \mathrm{~min}(S), 8.9 \mathrm{~min}$ $(R), 21.3 \min (7)$. 